Supporting Information

\title{
Partitioning, Desorption, and Dechlorination of a PCB Congener in Sediment Slurry Supernatants
}

Yuanxiang Fang and Souhail R. Al-Abed*

National Risk Management Research Laboratory, USEPA, 26 W. Martin Luther King Dr. Cincinnati, $\mathrm{OH} 45268$

fang.james@epa.gov, al-abed.souhail@epa.gov

- Corresponding author: Tel: 513-569-7849, Fax: 513-569-7879.

Environmental Science and Technology

May 26, 2007

Contents:

* Model for the dechlorination of PCBs in a DOM suspension in short-term experiments

* Determining rate constant for the dechlorination of PCBs by Fe/Pd in short-term experiments

* Model for the dechlorination of PCBs in a DOM suspension in long-term experiments

* Formulas used to calculate results presented in Table 1 (Table SI 1)

* Formulas used to calculate results presented in Table 2 (Table SI 2)

* A schematic of variables for modeling the dechlorination of PCBs in a DOM suspension in short-term experiments (Figure SI 1)

* A schematic of variables for determination of the dechlorination rate constant in shortterm experiments (Figure SI 2)

* The amounts of BP and 2-ClBP versus the initial amounts of 2-ClBP in a short-term dechlorination experiment (Figure SI 3).

* A schematic of variables used for modeling the dechlorination of PCBs in a DOM suspension in long-term experiments (Figure SI 4)

* A step-by-step schematic diagram for short-term experiments (Figure SI 5)

* A step-by-step schematic diagram for long-term experiments (Figure SI 6) 


\section{Model for the dechlorination of PCBs in a DOM suspension in short-term experiments}

Two rate constants can be defined and calculated for the dechlorination of a PCB in a DOM suspension. The first one is defined based on the concentration of the PCB in the suspension (which include both the DOM and aqueous phases), which is termed as the apparent rate constant. The second one is defined based on the concentration of the PCB in the aqueous phase. These two rate constants are different. The apparent rate constant is commonly measured (based on changes of the PCB concentration in the suspension), but its values vary with the DOM concentration in the suspension. The values of the second rate constant should not vary with the DOM concentration (because it is based on the PCB concentration in the aqueous phase), but these values are hard to obtained because it is difficult to completely separate the DOM and aqueous phases. In this section, we develop a model to relate these two rate constants. Based on this model, the second rate constant and the partition coefficient can be calculated from the apparent rate constant values measured in the short-term experiments in suspensions with different DOM concentrations.

A sediment DOM suspension in this study is a mixture of water and very fine sediment particles. These particles carry a fraction of organic matter (OM) that contributes the adsorption of PCBs on the particles. The PCB molecules partition between the DOM and aqueous phases in a DOM suspension. At equilibrium, the concentration of the PCB molecules that are adsorbed on the DOM particles, $C_{\mathrm{DOM}}\left(\mu \mathrm{mol} \mathrm{kg}_{\mathrm{DOC}}{ }^{-1}\right)$, can be related (Eq. SI 1) to the concentration of the PCB molecules in the aqueous phase, $C_{w}\left(\mu \mathrm{mol} \mathrm{L}{ }^{-1}\right)$, through a partition coefficient, $K_{\mathrm{DOM}}(\mathrm{L}$ $\mathrm{kg}_{\mathrm{DOC}^{-1}}{ }^{-1}$. Eq. SI 1 implies that all DOM is available and involved in PCB partitioning. And the PCB concentration in the suspension, $C_{\mathrm{L}}\left(\mu \mathrm{mol} \mathrm{L}{ }^{-1}\right)$, is related to the concentration of DOM in the suspension, [DOM] $\left(\mathrm{kg}_{\mathrm{DOC}} \mathrm{L}^{-1}\right)$, as expressed in Eq. SI 2 [1]. The fraction of PCB that is 
sorbed on DOM, $F_{\mathrm{DOM}}$, is defined in Eq. SI 3. The relationships between the above parameters are shown in the schematic in Figure SI 1.

$$
\begin{gathered}
C_{D O M}=K_{D O M} C_{w} \\
C_{L}=C_{w}+[D O M] C_{D O M}=\left(1+K_{D O M}[D O M]\right) \cdot C_{w} \\
F_{D O M}=\frac{K_{D O M}[D O M]}{1+K_{D O M}[D O M]} .
\end{gathered}
$$

For dechlorination of the PCB in a DOM suspension, the apparent first-order rate constant $k_{\mathrm{L}}\left(\mathrm{h}^{-1}\right)$ can be defined in Eq. SI 4 based on the change of $C_{L}$ with time, but the actual first-order rate constant $k_{\mathrm{w}}\left(\mathrm{h}^{-1}\right)$ can be defined in Eq. SI 5 which is based on the change of $C_{w}$ with time.

$$
\begin{aligned}
& k_{L}=-\frac{1}{C_{L}} \frac{d C_{L}}{d t} . \\
& k_{w}=-\frac{1}{C_{w}} \frac{d C_{w}}{d t}
\end{aligned}
$$

Because only the PCB molecules in the aqueous phase are immediately available for dechlorination in a short time $d t$, thus $d C_{w}=d C_{L}$ and $\frac{d C_{w}}{d t}=\frac{d C_{L}}{d t}$ in the suspension over a time interval $d t$. These conditions lead to the relationship between $k_{\mathrm{L}}$ and $k_{\mathrm{w}}$ as expressed in Eqs. SI 6 and SI 7.

$$
\begin{gathered}
k_{L}=-\frac{1}{C_{L}} \frac{d C_{L}}{d t}=-\frac{1}{C_{L}} \frac{d C_{w}}{d t}=\frac{1}{C_{L}} k_{w} C_{w}=\frac{k_{w}}{1+K_{D O M}[D O M],} \\
\frac{1}{k_{L}}=\frac{1}{k_{w}}+\frac{K_{D O M}}{k_{w}}[D O M] .
\end{gathered}
$$

The values of $k_{\mathrm{w}}$ and $K_{\mathrm{DOM}}$ can be obtained from the intercept and the slope of a fitting line of the $k_{\mathrm{L}}$ data in a plot of $1 / k_{\mathrm{L}}$ versus $[\mathrm{DOM}]$. 


\section{Determining rate constant for the dechlorination of PCBs by Fe/Pd in short-term experiments}

PCBs in aqueous solutions can be effectively dechlorinated to biphenyl on the surface of palladized zero-valent iron (Fe/Pd) [2-6]. It is believed that the dechlorination of PCBs occurs when they are adsorbed on the Fe/Pd surface. The Pd on the Fe surface acts as a collector of hydrogen gas (or dissolved active hydrogen species) that is produced by the corrosion reaction of iron. The PCBs that are adsorbed on the Fe/Pd surface are dechlorinated via a series of reactions. The reaction product, biphenyl, remains adsorbed on the surface or is released into the solution.

For the short-term dechlorination of 2-ClBP in pure water or in a DOM suspension in a $40 \mathrm{~mL}$ vial, a small amount of $\mathrm{Fe} / \mathrm{Pd}$ catalyst was added. At the end of experiment, the $\mathrm{Fe} / \mathrm{Pd}$ catalyst was separated from the water or the suspension. Extraction of biphenyls in these two parts was conducted separately. The amounts of biphenyls on the Fe/Pd catalyst and those in the water or the DOM suspension were obtained. In the following discussion, the $\mathrm{Fe} / \mathrm{Pd}$ is treated as one phase, the catalyst; the water or the DOM suspension is treated as a "single" phase, the liquid, because they were not separated and only the total concentration or the total amount of each compound in the suspension was measured and used. Therefore, the subscripts for the concentrations in the liquid, $\mathrm{w}$ for the water and L for the DOM suspension, are not listed in the following development.

Because significant amounts of biphenyl (and 2-ClBP) can be adsorbed on the Fe/Pd catalyst, the rate of dechlorination should be calculated based on the amounts of BP both in the liquid and on the catalyst. Therefore, the rate of dechlorination can be expressed in Eq. SI 8 using a first-order rate constant $k$ based on the weight of catalyst $\left(\mathrm{L} \mathrm{g}^{-1} \mathrm{~h}^{-1}\right)$, and a value of $k$ can 
be calculated using Eq. SI 9, which is based on the measured amounts of BP and 2-CIBP in each vial.

$$
\begin{gathered}
-V_{R} \frac{d C_{2-C I B P}}{d t}=k W C_{2-C I B P}=V_{R} \frac{d C_{B P}}{d t}+W \frac{d G_{B P}}{d t} \\
k=\frac{V_{R} C_{B P}+W G_{B P}}{V_{R}\left(C_{2-C B P P}+C_{B P}\right)+W\left(G_{2-C I B P}+G_{B P}\right)} \frac{V_{R}}{W t_{R}}=\frac{m_{B P}}{m_{2-C B P P}+m_{B P}} \frac{V_{R}}{W t_{R}}
\end{gathered}
$$

In the above equations, $C_{\mathrm{BP}}$ and $C_{2-\mathrm{ClBP}}(\mu \mathrm{M})$ are the concentrations of $\mathrm{BP}$ or 2-ClBP in the liquid; $G\left(\mu \mathrm{mol} \mathrm{g}{ }^{-1}\right)$ is the concentration of $\mathrm{BP}$ or 2-ClBP on $\mathrm{Fe} / \mathrm{Pd}$ catalyst (based on the weight of the catalyst); $m$ ( $\mu \mathrm{mol})$ is the total amount of $\mathrm{BP}$ or 2 -ClBP in the vial; $t_{\mathrm{R}}(\mathrm{h})$ is the experiment time $(10 \mathrm{~min}) ; V_{\mathrm{R}}(\mathrm{L})$ is the volume of liquid; $W(\mathrm{~g})$ is the amount of $\mathrm{Fe} / \mathrm{Pd}$. When the liquid is water (no DOM), the concentrations of biphenyls in the liquid are equivalent to $\mathrm{C}_{\mathrm{w}}$; when the liquid is a DOM suspension, the liquid concentrations are equivalent to $\mathrm{C}_{\mathrm{L}}$. The relationships between these variables are shown in the schematic in Figure SI 2.

One $k$ value can be calculated from each vial in a short-term experiment set, and an average $k$ value can be obtained for the dechlorination of 2-ClBP over a range of concentration in the set. This average carries a big deviation because the $k$ values for the vials with low initial concentrations have relative big uncertainties due to low conversions (about 10\%) and small initial amounts of 2-ClBP. Therefore, Eq. SI 9 was manipulated mathematically in the following section for calculating values of the rate constant with smaller deviations.

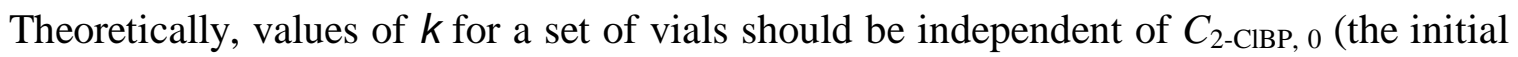
concentration of 2-ClBP) and of the ratio (in Eq. SI 9) of $m_{\mathrm{BP}}$ to $\left(m_{\mathrm{BP}}+m_{2-\mathrm{ClBP}}\right)$. Such independence is demonstrated in Figure SI 3. Figure SI 3 plots $m_{\mathrm{BP}}$ and $m_{\mathrm{BP}}+m_{2-\mathrm{ClBP}}\left(m_{\mathrm{BBP}}\right)$ versus the initial amounts of $2-\mathrm{ClBP}\left(m_{\mathrm{tBP}, 0}\right)$ in a set of vials. The suspensions in these vials 
contained $1 \mathrm{mg}_{\text {DOC }} \mathrm{L}^{-1} \mathrm{DOM}$ and the initial 2-ClBP concentrations were 2, 4, 8, 12, $16 \mu \mathrm{M}$. The values of $m_{\mathrm{tBP}, 0}$, calculated from the dilution ratios used in the preparation of the vials, are different from the $m_{\mathrm{tBP}}$ values due to experimental and analytical uncertainties. Figure SI 3 also demonstrates that the slope of the $m_{\mathrm{BP}}$ line (through the origin) is independent of the $m_{2-\mathrm{ClBP}, 0}$ values, which leads to Eqs. SI 10-11.

$$
\begin{gathered}
\left(\frac{\frac{m_{B P}}{m_{2-C I B P, 0}}}{\frac{m_{2-C I B P}+m_{B P}}{m_{2-C I B P, 0}}}\right)_{1}=\left(\frac{\frac{m_{B P}}{m_{2-C I B P, 0}}}{\frac{m_{2-C B B P}+m_{B P}}{m_{2-C I B P, 0}}}\right)_{2}=\ldots=\left(\frac{\frac{m_{B P}}{m_{2-C I B P, 0}}}{\frac{m_{2-C B P}+m_{B P}}{m_{2-C I B P, 0}}}\right)_{i}=\ldots=\frac{k_{B P}}{k_{t B P}} \\
\underline{k}=\frac{k_{B P}}{k_{t B P}} \frac{\bar{V}_{R}}{\bar{W} t_{R}}
\end{gathered}
$$

Where $\underline{k}$ is an average of the rate constant values in the vials. In these two equations, $i=1,2, \ldots$ designates different vials in the set; $k_{\mathrm{BP}}$ and $k_{\mathrm{tBP}}$ are the slopes of $m_{\mathrm{BP}}$ and $m_{\mathrm{tBP}}$ lines, respectively; $\bar{V}_{R}$ and $\bar{W}$ are respectively the average volume and $\mathrm{Fe} / \mathrm{Pd}$ amount in the vials. The $\underline{k}$ value carries a smaller deviation than the average of $k$ values calculated using Eq. SI 9, because the $k_{\mathrm{BP}}$ and $k_{\mathrm{tBP}}$ values carry smaller uncertainties than the individual values of $m_{\mathrm{BP}}$ and $m_{\mathrm{tBP}}$. The deviation of the $\underline{k}$ value can be estimated using the $95 \%$ confidence interval $( \pm \underline{k})$, which can be calculated using Eq. SI 12.

$$
\pm \underline{k}=\frac{\bar{V}_{R}}{\bar{W} t_{R}} \frac{ \pm k_{B P} k_{t B P}+k_{B P}\left( \pm k_{t B P}\right)}{k_{t B P}^{2}}
$$

where $\pm k_{\mathrm{BP}}$ and $\pm k_{\mathrm{tBP}}$ are the $95 \%$ confidence intervals of $k_{\mathrm{BP}}$ and $k_{\mathrm{tBP}}$, respectively, and their values are estimated using $t_{\mathrm{v}} S_{\mathrm{b}}$, where $t_{\mathrm{v}}$ is the critical value of the $\mathrm{t}$ statistic and $S_{\mathrm{b}}$ is the standard error in the slope. 
Based on Eqs. SI 4. SI 5, and SI 8, for the dechlorination of PCBs by Fe/Pd in pure water (no DOM), the relationships between $k$ and $k_{\mathrm{w}}$ as well as between $\underline{k}$ and $\underline{k}_{\mathrm{w}}$ are provided in SI 13a. For the dechlorination of PCBs by Fe/Pd in a DOM suspension, the relationships between $k$ and $k_{\mathrm{L}}$ as well as between $\underline{k}$ and $\underline{k}_{\mathrm{L}}$ are provided in SI $13 \mathrm{~b}$.

$$
\begin{gathered}
k_{w}=k \frac{W}{V_{R}}, \underline{k}_{w}=\underline{k} \frac{\bar{W}}{\bar{V}_{R}} \text { (for dechlorination in pure water). } \\
k_{L}=k \frac{W}{V_{R}}, \underline{k}_{L}=\underline{k} \frac{\bar{W}}{\bar{V}_{R}},(\text { for dechlorination in a DOM suspension). }
\end{gathered}
$$

\section{Model for the dechlorination of PCBs in a DOM suspension in long-term experiments}

This model was developed to relate the time constant or the apparent rate constant for the dechlorination and disappearance of PCBs in a DOM suspension to the fundamental physical parameters such as the dechlorination rate constant, the desorption rate constant, and the partition coefficient. Values of these fundamental parameters can be estimated based on this model from the dependence of the apparent rate constant values measured in long-term experiments on the DOM concentration.

For heterogeneous catalytic dechlorination of PCB (by Fe/Pd) in a DOM suspension, only the PCB molecules in the aqueous phase is directly subjected to dechlorination, and the depletion of PCB molecules in the aqueous phase results in a concentration gradient between the aqueous and DOM phases which leads to the desorption of PCB in DOM. The rate of disappearance of the PCB in the suspension is ultimately determined by the rate of dechlorination in the aqueous 
phase. The governing equations for the change in concentrations of the PCB in the DOM phase $\left(C_{\text {DOM }}\right)$, the aqueous phase $\left(C_{\mathrm{w}}\right)$, and the suspension $\left(C_{\mathrm{L}}\right)$ can be expressed as in Eqs. SI 14 to SI 15:

$$
\begin{gathered}
\frac{d C_{D O M}(t)}{d t}=-k_{d}\left[C_{D O M}(t)-K_{D O M} C_{w}(t)\right], \\
\frac{d C_{w}(t)}{d t}=-k_{w} C_{w}(t)+[D O M] \frac{d C_{D O M}(t)}{d t}, \\
\frac{d C_{L}(t)}{d t}=-k_{w} C_{w}(t),
\end{gathered}
$$

where $k_{\mathrm{d}}\left(\mathrm{h}^{-1}\right)$ is the rate constant for the desorption of the PCB from DOM to the aqueous phase. The initial conditions are $C_{\mathrm{DOM}}(0)=C_{\mathrm{DOM}, 0} ; C_{\mathrm{w}}(0)=C_{\mathrm{w}, 0} ; C_{\mathrm{L}}(0)=C_{\mathrm{L}, 0} ;$ and $C_{\mathrm{L}, 0}=C_{\mathrm{w}, 0}+$ $[\mathrm{DOM}] C_{\mathrm{DOM}, 0}$. Here $C_{\mathrm{DOM}, 0}\left(\mu \mathrm{mol} \mathrm{\textrm {kg } _ { \mathrm { DOC } }}{ }^{-1}\right), C_{\mathrm{w}, 0}\left(\mu \mathrm{mol} \mathrm{L}{ }^{-1}\right)$ and $C_{\mathrm{L}, 0}\left(\mu \mathrm{mol} \mathrm{L}{ }^{-1}\right)$ are the initial concentrations of the PCB in the DOM phase, the aqueous phase, and the suspension. The relationships between these variables are shown in the schematic in Figure SI 3.

This model assumes that the PCB is at equilibrium between the DOM and aqueous phases in the initial suspension, that the adsorption isotherm is linear in the range and is not affected by the production of BP. The first assumption was verified by the data obtained in the short-term experiments. The second one is reasonable because the concentrations of the PCB and BP were very low in the experiments.

The analytical solutions for $C_{\mathrm{DOM}}, C_{\mathrm{w}}$, and $C_{\mathrm{L}}$ as functions of time are available. The analytical solution for $C_{L}(t)$ can be arranged in the following equation in a form of a two compartment model.

$$
\frac{C_{L}(t)}{C_{L}(0)}=\left(f_{1} e^{-k_{1} t}+f_{2} e^{-k_{2} t}\right)
$$


where $k_{1}=\frac{1}{2}\left(Q+\sqrt{Q^{2}-4 k_{w} k_{d}}\right)$;

$$
\begin{gathered}
k_{2}=\frac{1}{2}\left(Q-\sqrt{Q^{2}-4 k_{w} k_{d}}\right) \\
f_{1}=1-f_{2} \\
f_{2}=\frac{k_{1}-k_{w} /\left(1+[D O M] K_{D O M}\right)}{k_{1}-k_{2}} ; \\
Q=k_{w}+k_{d}\left(1+[D O M] K_{D O M}\right)
\end{gathered}
$$

Here $\mathrm{Q}$ is a model parameter that is used to simplify the expressions. Eq. SI 17a describes the profile of $C_{\mathrm{L}}(t)$ into two phases: the dechlorination of 2-ClBP in the aqueous phase and the desorption of 2-CIBP from DOM. Parameters $k_{1}\left(\mathrm{~h}^{-1}\right)$ and $f_{1}$ are respectively the time constant and pre-exponential coefficient for the first phase, and parameter $k_{2}\left(\mathrm{~h}^{-1}\right)$ and $f_{2}$ are respectively the time constant and pre-exponential coefficient for the second phase. The time constant $k_{2}$ can be approximately related to the partition coefficient $\left(K_{\mathrm{DOM}}\right)$, desorption rate constant $\left(k_{\mathrm{d}}\right)$, and the dechlorination rate constant $\left(k_{\mathrm{w}}\right)$ in the following simplified but physically meaningful equation

$$
\frac{1}{k_{2}} \cong \frac{1}{k_{d}}+\frac{K_{D O M}}{k_{w}}[D O M]
$$

The value of $k_{2}$ can be calculated based on the disappearance of PCB in the DOM suspension, which is equal to the value of the apparent rate constant $\left(k_{\mathrm{obs}}\right)$ in the main text. Based on the dependence of $k_{2}$ data on [DOM], the values of the primary physical parameters such as $k_{\mathrm{d}}$ can be estimated.

This model uses one concentration of the PCB in the DOM phase and describes a one-step transfer process (desorption) of PCB molecules from the DOM phase to the aqueous phase. The 
model implies that the concentration of the PCB in the DOM phase is uniform and that there is no diffusion of PCB molecules inside the DOM particles, which is equivalent to the statement that all the PCB molecules are on the external surface of the DOM particles. Therefore, this model considers only the "fast" sediment compartment. The "slow" sediment compartment is not included because a DOM suspension contains a very small fraction (less than $10 \mathrm{mg}_{\mathrm{DOM}} \mathrm{L}^{-1}$ ) of "dissolved" organic matters in forms of very fine particles and these fine particles have an extremely small amount of mass but a huge surface area. As a result, most of the PCB molecules are adsorbed on the external surface of the DOM particles.

This model should be used only for desorption and heterogeneous catalytic dechlorination of PCBs in DOM suspensions. Without the inclusion of the "slow" sediment compartment, this model should not be used for sediment slurry systems.

\section{Literature Cited}

(1) Gschwend, P. M.; Wu, S. C., On the constancy of sediment-water partition coefficients of hydrophobic organic pollutants. Environ. Sci. Technol. 1985, 19, 90-96.

(2) Grittini, C.; Malcomson, M.; Fernando, Q.; Korte, N., Rapid dechlorination of polychlorinated biphenyls on the surface of a $\mathrm{Pd} / \mathrm{Fe}$ bimetallic system. Environ. Sci.

Technol. 1995, 29, 2898-2900.

(3) West, O. R.; Liang, L.; Korte, N. E.; Fernando, Q.; Clausen, J. L. Degradation of Polychlorinated Biphenyls (PCBs) Using Palladized Iron; ORNL/TM-13217; Oak Ridge National Laboratory. 1996.

(4) Korte, N.; Liang, L.; Muftikian, R.; Grittini, C.; Fernando, Q., Dechlorination of hydrocarbons palladized iron utilised for ground water purification. Platinum Metals Review 1997, 41, 2.

(5) Kim, Y.-H.; Shin, W. S.; Ko, S.-O., Reduction dechlorination of chlorinated biphenyls by palladized zero-valent metals. J. Environ. Sci. Health., Part A 2004, 39, 1177-1188. 
(6) Lowry, G. V.; Johnson, K. M., Congener-specific dechlorination of dissolved PCBs by microscale and nanoscale zerovalent iron in a water/methanol solution. Environ. Sci. Technol. 2004, 38, 5208-5216. 
Table SI 1. Formulas used to calculate results presented in Table 1.

$$
\begin{gathered}
m_{2-C I B P, i 0}=V_{R} C_{L 2-C I B P, i 0}, i=1, N ; N=5 \\
m_{2-C I B P, i}=V_{R} C_{L 2-C I B P, i}+W G_{2-C I B P, i} \\
m_{B P, i}=V_{R} C_{L B P, i}+W G_{B P, i}
\end{gathered}
$$

$$
\text { Recovery } \left.(\%)=\frac{1}{N} \sum_{i=1}^{N} \text { (Recovery }\right)_{\mathrm{i}}=\frac{1}{N} \sum_{i=1}^{N} \frac{m_{B P, i}+m_{2-C I B P, i}}{m_{2-C I B P, i 0}} \times 100
$$

$$
\text { Conversion }(\%)=\frac{1}{N} \sum_{i=1}^{N}(\text { Conversion })_{\mathrm{i}}=\frac{1}{N} \sum_{i=1}^{N} \frac{m_{B P, i}}{m_{2-C I B P, i 0}} \times 100
$$

Biphenyls on Fe/Pd $(\%)=\frac{1}{N} \sum_{i=1}^{N}(\text { Biphenyls on Fe/Pd })_{i}=\frac{1}{N} \sum_{i=1}^{N} \frac{W\left(G_{B P, i}+G_{2-C I B P, i}\right)}{m_{B P, i}+m_{2-C I B P, i}} \times 100$

$2-\mathrm{ClBP}$ on $\mathrm{Fe} / \mathrm{Pd}(\%)=\frac{1}{N} \sum_{i=1}^{N}(2-\mathrm{ClBP} \text { on } \mathrm{Fe} / \mathrm{Pd})_{\mathrm{i}}=\frac{1}{N} \sum_{i=1}^{N} \frac{G_{2-C I B P, i}}{G_{B P, i}+G_{2-C I B P, i}} \times 100$

$$
2-\mathrm{ClBP} \text { in aqueous phase }(\%)=\left(1-F_{D O M}\right) \times 100=\frac{1}{1+K_{D O M}[D O M]} \times 100
$$

Conversion of $2-\mathrm{ClBP}$ in aqueous phase $(\%)=\frac{\text { Conversion }}{2-\mathrm{ClBP} \text { in aqueous phase }} \times 100$ 
Table SI 2. Formulas used to calculate results presented in Table 2

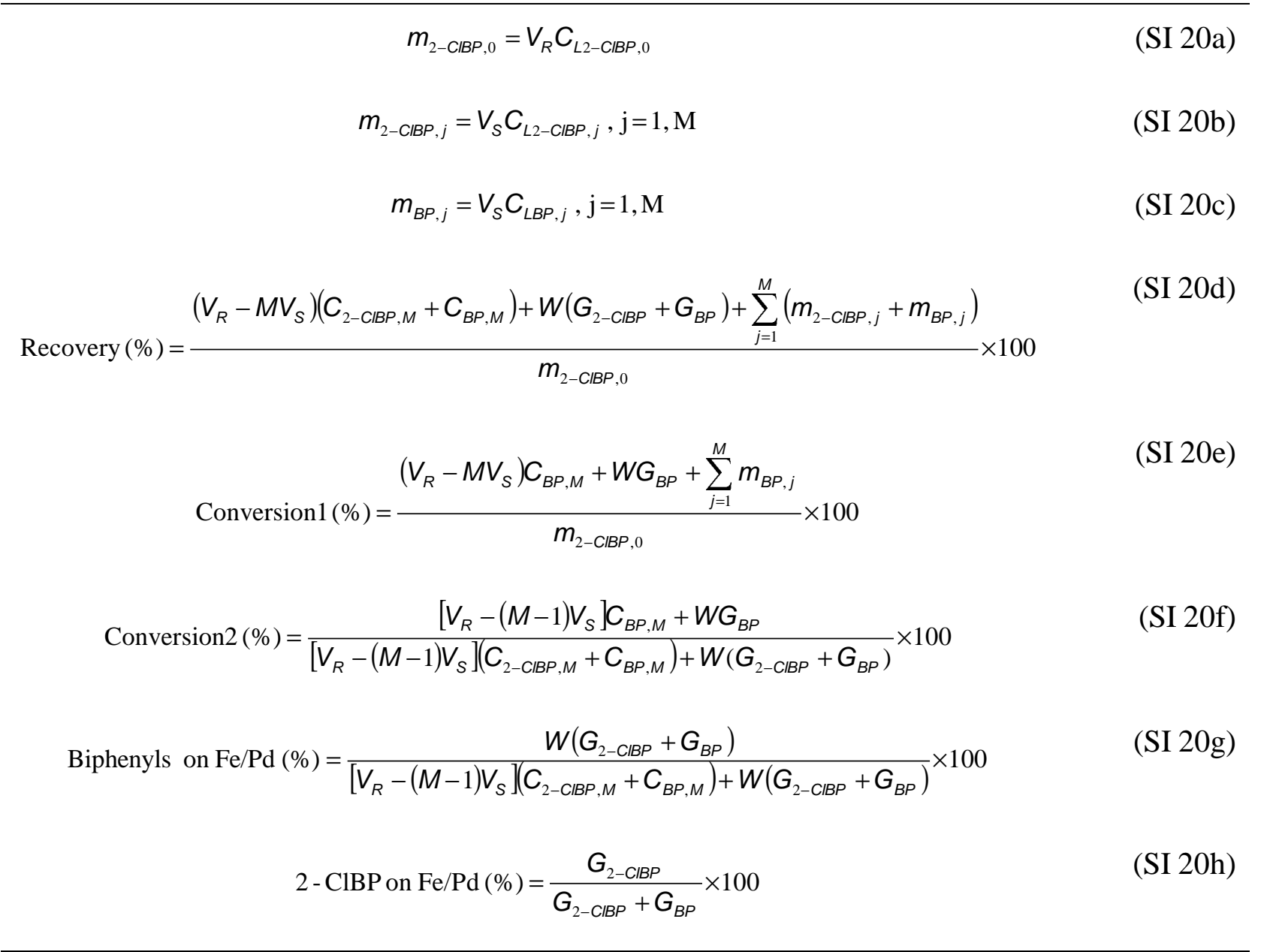




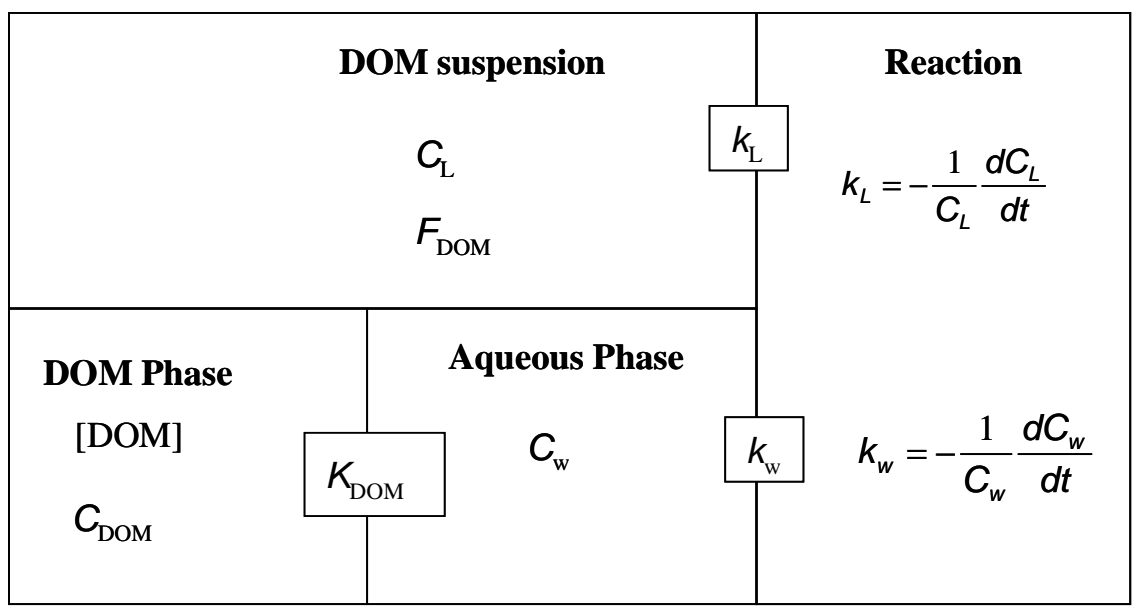

Figure SI 1. A schematic of variables used for modeling the dechlorination of PCBs in a DOM suspension in short-term experiments. 


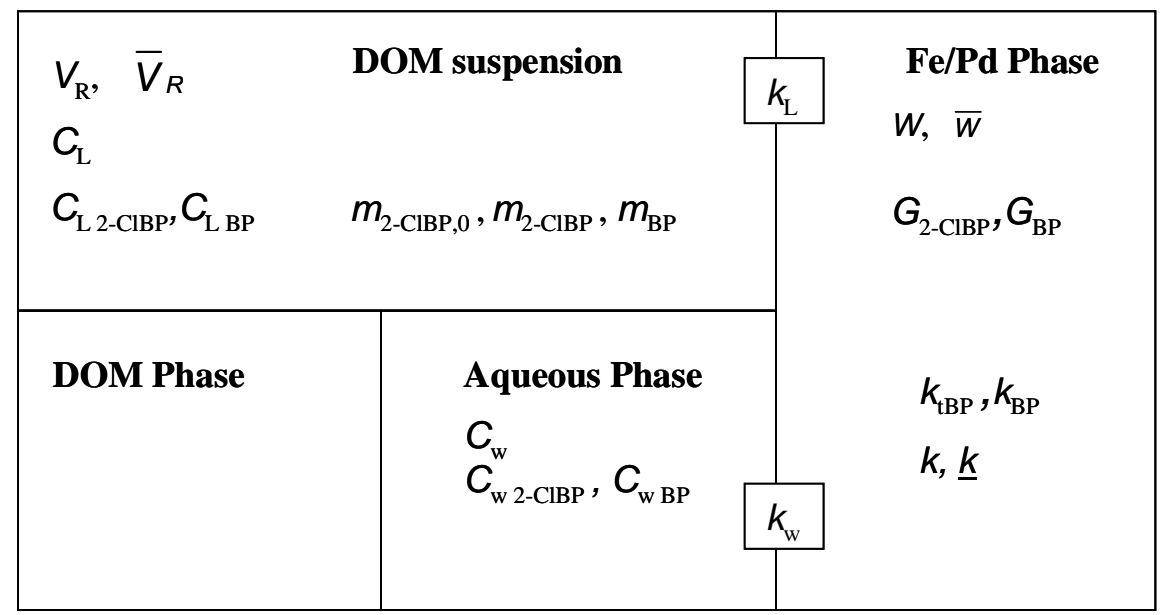

Figure SI 2. A schematic of variables used for determination of the dechlorination rate constant in short-term experiments. 


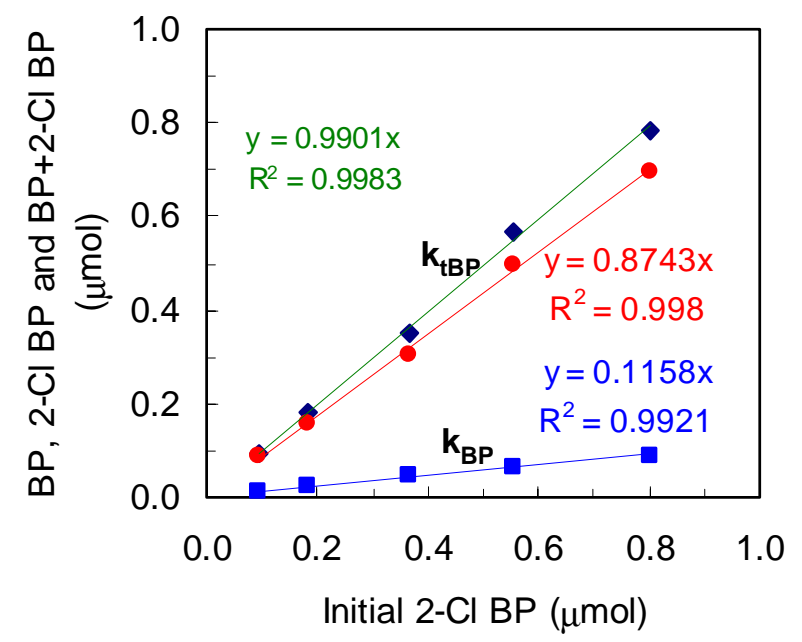

Figure SI 3. The amounts of BP $(\bullet), 2-\mathrm{ClBP}(\bullet)$, and BP +2 -ClBP $(\bullet)$ versus the initial amounts of 2-ClBP in a set of 10 min short-term dechlorination of 2-ClBP by Fe/Pd. The suspensions in the five vials contained $1 \mathrm{mg}$ DOC $\mathrm{L}^{-1} \mathrm{DOM}$ and the initial 2-ClBP concentrations were 2, 4, 8 , $12,16 \mu \mathrm{M}$. 


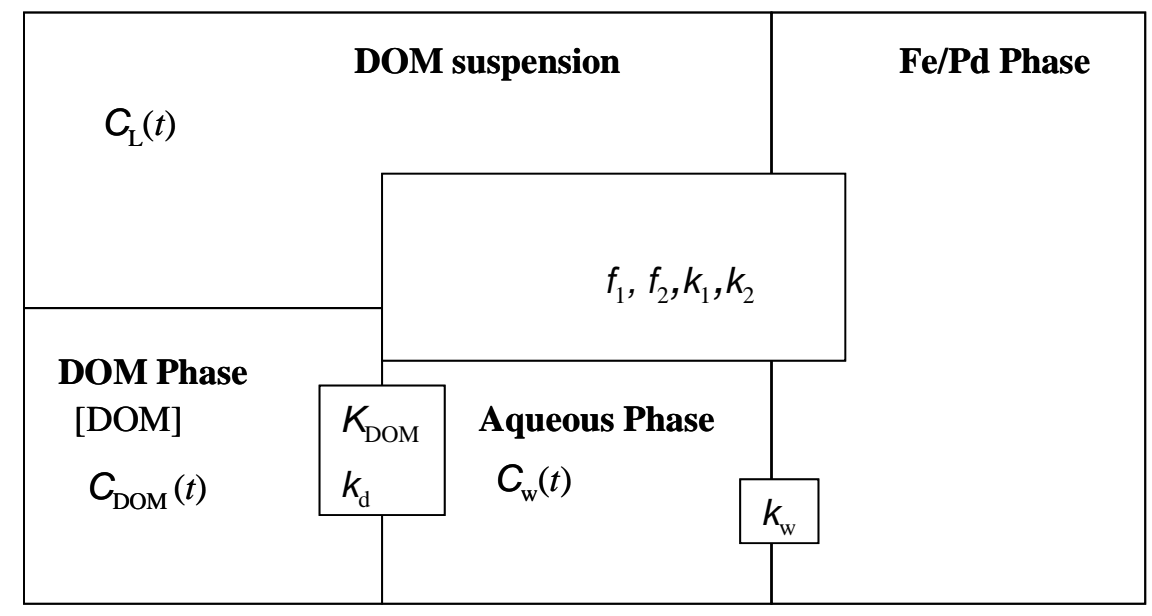

Figure SI 4. A schematic of variables used for modeling the dechlorination of PCBs in a DOM suspension in long-term experiments. 


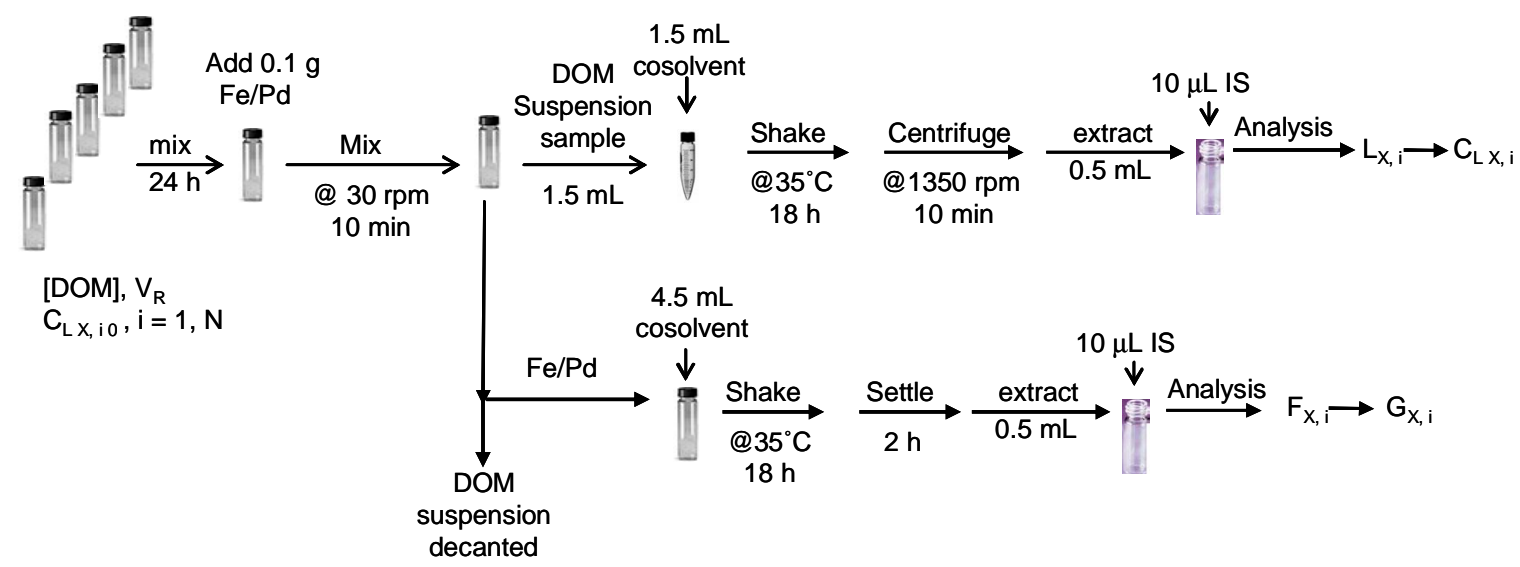

Figure SI 5. A step-by-step schematic diagram for short-term experiments. $C_{\mathrm{L} \text { X, i0 }}\left(\mu \mathrm{mol} \mathrm{L}{ }^{-1}\right)$ is the initial concentration of $\mathrm{X}$ in the DOM suspension in the $\mathrm{i}^{\text {th }}$ vial; $C_{\mathrm{LX}, \mathrm{i}}\left(=\mathrm{L}_{\mathrm{X}}, \mathrm{i} \mu \mathrm{mol} \mathrm{L} \mathrm{L}^{-1}\right)$ is the concentration of $\mathrm{X}$ in the DOM suspension in the $\mathrm{i}^{\text {th }}$ vial; $F_{\mathrm{X}, \mathrm{i}}\left(\mu \mathrm{mol} \mathrm{L}^{-1}\right)$ and $L_{\mathrm{X}, \mathrm{i}}\left(\mu \mathrm{mol} \mathrm{L} \mathrm{L}^{-1}\right)$ are the concentrations of $\mathrm{X}$ in the cosolvent extracts of the Fe/Pd particles and the DOM samples, respectively; $G_{X, i}\left(=4.5 \times 10^{-3} F_{X, i} / W \mu m o l g^{-1}\right)$ is the amount of $X$ per unit of $F e / P d$ in the $i^{\text {th }}$ vial; IS designates the internal standard; $i(=1,2, \ldots N)$ is the index of the five vials in a set ; $N$ is the number of vials in each set; $V_{\mathrm{R}}$ is the volume of the DOM suspension in each vial; $W(\approx 0.1$ $\mathrm{g}$ ) is the amount of $\mathrm{Fe} / \mathrm{Pd}$ added to each vial; $\mathrm{X}=\mathrm{BP}$ or $2-\mathrm{ClBP}$. 


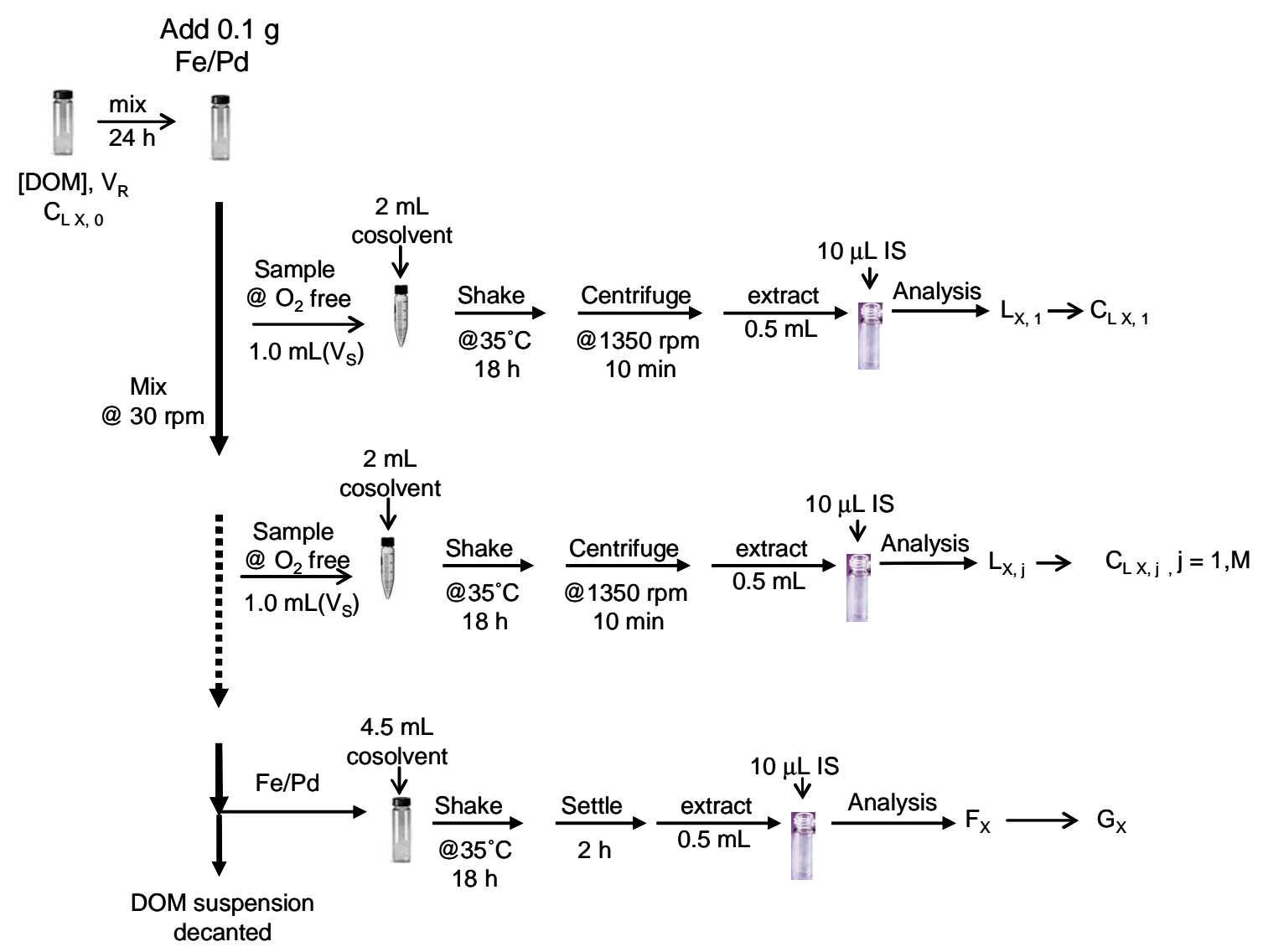

Figure SI 6. A step-by-step schematic diagram for long-term experiments. $C_{\mathrm{L} \mathrm{X}, 0}\left(\mu \mathrm{mol} \mathrm{\textrm {L } ^ { - 1 }}\right)$ is the initial concentration of $\mathrm{X}$ in the DOM suspension; $C_{\mathrm{LX}, \mathrm{j}}\left(=2 L_{\mathrm{X}, \mathrm{j}} \mu \mathrm{mol} \mathrm{L^{-1 }}\right)$ is the concentration of $\mathrm{X}$ in the $f^{\text {th }}$ DOM suspension sample; $F_{\mathrm{X}}\left(\mu \mathrm{mol} \mathrm{L} \mathrm{L}^{-1}\right)$ and $L_{\mathrm{X}, \mathrm{j}}\left(\mu \mathrm{mol} \mathrm{L} \mathrm{L}^{-1}\right)$ are the concentrations of $\mathrm{X}$ in the cosolvent extracts of the Fe/Pd particles and the $\mathrm{j}^{\text {th }} \mathrm{DOM}$ sample, respectively; $G_{\mathrm{X}}\left(=4.5 \times 10^{-3} F_{\mathrm{X}} / W \mu \mathrm{mol} \mathrm{g} \mathrm{g}^{-1}\right)$ is the amount of $\mathrm{X}$ per unit of $\mathrm{Fe} / \mathrm{Pd}$; IS designates the internal standard; $j(=1,2, \ldots M)$ is the index of the DOM samples; $M$ is the total number of DOM samples taken in the experiment; $V_{R}(\mathrm{~mL})$ is the initial volume of the DOM suspension in each vial; $V_{\mathrm{S}}(=1 \mathrm{~mL})$ is the volume of each DOM sample; $W(\approx 0.1 \mathrm{~g})$ is the amount of $\mathrm{Fe} / \mathrm{Pd}$ added to the vial; $\mathrm{X}=\mathrm{BP}$ or 2-ClBP. 